\title{
Strategies for Green Economy in China
}

\author{
Alina Steblyanskaya \\ Associate Professor, School of Economics and Management, alina_steblyanskaya@hrbeu.edu.cn
}

Ai Mingye*

Associate Professor, School of Economics and Management, aimingye@hrbeu.edu.cn

Harbin Engineering University, Nangang district, Nantongdajie 145, Harbin, Heilongjiang, 150001, China

Vladimir Bocharnikov

Professor, Wildlife Ecology and Conservation Laboratory, vbocharnikov@mail.ru

Pacific Geographical Institute, Far East Branch of the Russian Academy of Science, 7, Radio str., Vladivostok 690041, Russian Federation

\author{
Artem Denisov \\ Associate Professor, Department of Computer Science, iptema@yandex.ru \\ Kostroma State University, 17 Dzerzhinskogo str., Kostroma 156005, Russian Federation
}

\begin{abstract}
$\mathrm{T}$

The transition to a "green" economic model is a complex strategic task that requires a combination of two previously incompatible development vectors: maintaining dynamic economic growth and preserving the natural environment on a long-term basis. No country has yet been able to cope with such complexity, nevertheless, the active search for a new balanced model continues, with the development of appropriate strategies. China is among the countries moving in this direction.

The article analyzes the influence of social, economic, and environmental factors upon the prospects for the development of a green economy and the preservation of natural areas in China. The dynamics of changes in the ecological situation from 1970 to 2018 is investigated. The authors propose a methodology for assessing the state of the environment based on demographic dynamics, economic

indicators, and the level of technological development. Over the past 50 years, China has experienced intensive industrial development as a result of which the degradation of valuable natural assets is increasing in most regions. At the same time, efforts are being made in a number of provinces to remedy the situation through the formulation of new policies, the first results of which have been already visible. The government has established a new environmental legislation designed to scale the green practices of the pioneering regions throughout the country, including the trend toward the de-urbanization of individual megacities and others. The implementation of this strategy will be facilitated by the expansion of interdisciplinary scientific research, the development of complex technological solutions, and development programs that simultaneously take into account various factors.
\end{abstract}

Keywords: green economy; innovation strategies; sustainability; China wilderness areas; Kaya equation; wilderness area ratio (RWA); protected wilderness area ratio (PWA)
Citation: Steblyanskaya A., Ai M., Bocharnikov V., Denisov A. (2021) Strategies for Green Economy in China. Foresight and STI Governance, 15(1), 74-85. DOI: 10.17323/25002597.2021.1.74.85

* corresponding author

( 2021 by the authors. This article is an open access article distributed under the terms and conditions of the Creative Commons Attribution (CC BY) license (http://creativecommons.org/licenses/by/4.0/). 
$\mathrm{N}$ owadays it is a common knowledge that "green" is a sustainable and sensitive economy that creates more useful instruments for humanity without causing ecological damage [Costanza, 1989; Daly, 2007]. German scientist Hugo Wilhelm Conwentz (1855-1922) and his follower Ivan Borodin were the first who at the end of 19th - beginning of $20^{\text {th }}$ century started developing a nature conservation methodology, based on cultural and moral principles [Williams, 1996]. In recent times, all economic studies on the subject have aimed at finding answers to the questions emphasized in "The Limits to Growth" [Meadows et al., 1972; Hall et al., 2014]. There is a challenge to find a way to create a sustainable community and an improved quality of life without causing damage to nature. Preserving the natural productivity of ecosystems at the geopolitical level belongs to the concept of natural capital, although, we have not seen the ideas of sustainable development brought together with real actions by business and governments, individuals, and corporations in the economic sector [Ward et al., 2016]. The UN included wilderness ecosystems as priority for conservation ${ }^{1}$.

In recent years, mainly since the $12^{\text {th }}$ five-year plan period, the enhanced measures including legislation, policy, regulatory, and economic means have been applied by the Chinese government in dealing with environmental problems. China's $12^{\text {th }}$ five-year plan explicitly defined plans for the ultimate control of wilderness territory defenses and the optimization intensity of energy and water conservation [Tang et al., 2018]. However, the synergy between wilderness conservation, energy efficiency, and economic growth has rarely been taken into consideration $[X i$, 2020]. China's national policies promote high levels of economic growth, transforming China into a "world factory" since its opening and reform, but at a high cost in terms of sustainable energy and ecological protection. China faces a dilemma in upgrading its economy, energy system, and environmental security [Tang et al., 2015]. Given this situation and concerning the demand of the government at different levels for environmental policy tools, the environmental policy research projects encompassing a wide range of subjects are carried out in China, especially those concerning nature conservation. China, as a seriously changed territory in terms of wilderness, needs to develop new complex models for the evaluation of how growth influences nature protection [Bocharnikov, 2019]. Indeed, the main problem is to increase data availability concerning wilderness areas [Frelich, Reich, 2009; Kuiters et al., 2013]. Globally, the existing protected areas and Aichi Target 11 are not enough to slow the downward trends for biodi- versity [Cao et al., 2019]. Targets must be set for protected areas and the protected areas system should be further expanded [Mittermeier et al., 2003].

Wilderness protection is increasingly important in the era of the Sixth Extinction and the Anthropocene [Sandbrook, 2015]. Cao Yue et al. in their research emphasized that wilderness areas have great value, however, China has not yet conducted an actual wilderness resources inventory [Cao et al., 2019]. The concept of wilderness is lacking any accepted definition [Nash, 2014]. Thus, some research studies associated economic growth and urbanization with devastated lands and tried to find methods to define green urbanization processes [Shi et al., 2016]. For example, there is a study for Portugal that uses special indicators to evaluate the diversity, rareness, and vulnerability of species in the National Park Peneda-Geres [Ceauşu et al., 2015]. Steblyanskaya and Bragina examined how the largest companies could lead financial growth and pay attention to the energy, social, and ecological factors leading to sustainability and positive impacts for nature conservation [Steblyanskaya et al., 2019]. In the same way, biophysical economics tries to find a path toward nature sustainability [Cleveland et al., 1984; Palmer, 2018]. There must be a long-term co-integration between nature conservation and other green investments [Costanza et al., 2015, 2017].

There are numerous useful initiatives in the world for developing the green economy and minimizing economic and social impact upon nature. Thus, in the US, wilderness values span the economic, environmental, and cultural spheres [Proctor, 2021]. The US National Wildlife Federation's first priority was to secure the passage of legislation that supported the North American Wildlife Conservation Model. The Federal Wildlife Restoration Assistance Act of 1937 resulted in the restoration of dozens of birds and mammals and stimulated countless conservation partners' work in recent decades. The Wildlife Act of 1964, championed by the Wildlife Society, established values still used today in state conservation in America. Since 2009, the USDA has provided more than 200 environmental innovation grants to support the search for new conservation solutions in a rapidly growing economy ${ }^{2}$.

In Canada, environmental activities tend to be carried out in waves, closely associated with periods of activation of environmental sentiments in society [Locke, 2009]. One of the mechanisms for protecting protected areas in the Canadian Arctic was land ownership registration [Sahanatien, 2007]. Currently, Canada has approved a plan for climate change, green growth, and the conservation of natural values ${ }^{3}$.

\footnotetext{
${ }^{1}$ For more details see the UNCED Convention on Biological Diversity (1992). https://www.cbd.int/doc/legal/cbd-en.pdf (date of access: 18.12.2020)

${ }^{2}$ US Department of agriculture https://www.usda.gov/topics/conservation (date of access 29.01.2021).

${ }^{3}$ Government of Canada https://www.canada.ca/en/environment-climate-change/news/2019/06/canadas-plan-for-climate-change-and-clean-growth.html (date of access 29.01.2021).
} 
In 2002, Germany adopted the National Sustainable Development Strategy. Germany has also launched major cross-cutting initiatives in biodiversity, climate change, energy efficiency, and resource efficiency. The Energy Concept, the German Resource Efficiency program, and other ambitious environmental programs have helped Germany to significantly improve the energy efficiency, resource and carbon efficiency of the economy.

The United Arab Emirates supports sustainable development and provides a safe environment. Among the Gulf countries, the United Arab Emirates has been a leader in the application of clean technologies and alternative energy sources in the past few years [Vaghefi et al., 2015].

A long-term African initiative, Great Green Wall (GGW), is being promoted to reduce desertification in the Sahel by planting a wide, uninterrupted strip of trees from Senegal to Djibouti. As a result, an integrated approach to large-scale land restoration, based on rural communities, led to the greening of approximately 12,000 hectares of degraded land between 2015 and 2017. However, the Great Green Wall initiative is still far from completion given of the creation of vast mosaics of green and productive landscapes where communities can thrive [Connor, Ford, 2014].

In this paper, the authors tested how economic, social, and environmental indicators influence Chinese wilderness areas' sustainable conservation. As a result of evaluating the ratio of a wilderness area (RWA), the ratio of protected wilderness area (PWA), and the ratio for wilderness area to population (WAP) for every China province, the authors obtained forecast models to predict the wilderness situation until 2030. The models' results can provide valuable information for the management of natural and protected areas. It is necessary to draw a general line, where on one side is economically sustainable growth and on the other, wilderness conservation. If a territory has economic growth with a high population density, then wilderness faces restrictions for conservation.

As for the research goals, the authors aimed at developing a protected wilderness area formula using similar logic to Kaya's equation. The equation components were further analyzed using principal component isolation analysis (PCA) and seasonal autoregressive integrated moving average model (SARIMA). Several research studies use such methods when analyzing components influencing ecological factors [Kosman et al., 2019; Palmer, 2018; Rasker, 2006; Wuerthner, 2018]. However, only a handful of studies develop and make use of variants of the Kaya identity formula. Thus, the authors found it useful to create a formula using the same logic as the Kaya equation for analyz- ing components influencing China's wilderness situation. The presented methods and results will be useful not only in the context of studying the influence of economic and social factors upon the natural environment of China, but also in the context of studying other countries' green sustainable growth.

\section{Methodology \\ Data Availability}

Research data sources are described in Table 1, including land use, railway, road, population density, and investments in environmental protection. The authors use China inland data. Environmental data was obtained from the China Environmental Statistical Books, from 1970 to 2018, and from the EPS database ${ }^{4}$. Economic and social data were obtained from the China Statistical Data Books, 1970-2018. RWA/RPWA/WAP calculations were done based on Vladimir Bocharnikov's methodology [Baklanov et al., 2018; Bocharnikov, Huettman, 2019]. Python 3.4 was used for modeling 5 .

\section{Kaya Identity for Wilderness Conservation}

The identity developed by Yoichi Kaya is a specific application of the I = PAT identity, which relates human impact upon the environment (I) to the product of population (P), affluence (A), and technology $(\mathrm{T})$. The authors were inspired by the Kaya formulation [Kaya, Yokoburi, 1997]. The Kaya identity is a tool used to understand and measure how $\mathrm{CO}_{2}$ emissions and their underlying drivers change [Lester, Finan, 2009]. GDP growth is composed of GDP per-capita and population growth is connected to emissions with the Kaya identity [Palmer, 2018]. The Kaya identity states that total $\mathrm{CO}_{2}$ emissions are the product of population, GDP per-capita, energy intensity, and carbon intensity (Equation 1.)

$F=P \times G / P \times E / G \times F / E$,

Where,

$F-\mathrm{CO}_{2}$ emissions from human-made sources

$P$ - Population

G- Gross Domestic Product (GDP)

E - Energy consumed

Thus, using the Kaya equation, we could analyze $G / P=$ GDP per capita, $E / G=$ Energy Intensity of GDP, $F / E=$ Carbon Intensity of the energy supply.

In this study, the authors used the same logic and modified Kaya identity formula into the Protected Wilderness Areas (further - PWA) equation (Equation 2):

\footnotetext{
${ }^{4}$ EPS database http://olap.epsnet.com.cn (date of access: 29.01.2021).

5 The Python code is written for calculating and the paper data are available at the GitHub at the following link: https:/github.com/rufimich/enviromental_ paper (date of access: 29.01.2021).
} 
$P W A=P W A / W A \times W A / L A \times L A /(R L+H L) \times$ $(R L+H L) / G D P \times G D P / E C \times E C / W W \times W W / T I E P C$ $\times T I E P C / P \times P$

Where,

$P W A$ - Protected wilderness area;

$W A-$ Wilderness area

$L A-$ Land area

$R L$ - Railway length

$H L$ - Highway length

GDP - Gross Domestic Product

$E C-$ Energy consumption

$W W$ - Wastewater discharge

TIEPC - Total investments in environmental pollution control

$P$ - Population

The wilderness area ratio (RWA), protected wilderness area ratio (PWA), and protected wilderness area (sq.km) divided by the $\mathrm{P}$ - population (mln. people) (WAP) (Equations 3-5) were calculated based on Vladimir Bocharnikov's methodology [Bocharnikov, Huettman, 2019; Baklanov et al., 2018].

$R W A=W A / L A$,

Where WA - Wilderness area (sq.km), LA - Land area (China) (sq.km).

$P W A=P W A / W A$,

Where $P W A$ - Protected wilderness area (sq.km), $W A-$ Wilderness area (sq.km)

$W A P=W A / P$,

Where WAP - Protected wilderness area (sq.km), $P$ - population (mln. people).

The methodological research scheme is presented in Figure 1.

The authors identified the three indices (RWA/PRWA/ WAP) for the evaluation of wilderness conservation. Detailed indicators can be seen in Table 1.

It was assumed that some trends determine the progress of wilderness conservation in Chinese provinces. Trends are independent of one another. As a result, it can be argued that every trend changes in its space, represented by one or more dimensions (components-vectors). Due to the independence of the trends, it can be observed that their space or "orthogonality" to each other is zero.

To remove economies of scale in the indicators, the authors used normalization. To do this, the authors used a reduction method for the standard normal distribution [Zimmerman, 2003].

$Z_{i j}=\frac{x_{i j}-\bar{x}_{j}}{\sigma_{j}}, i=1,2 \ldots, n ; j=1,2 \ldots p$,

Where,

$\bar{x}_{j}=\frac{\sum_{i=1}^{n} x_{i j}}{n}, \sigma_{j}=\sqrt{\frac{\sum_{i=1}^{n}\left(x_{i j}-\bar{x}_{j}\right)^{2}}{n-1}}$,
For the defined trends concerning the wilderness situation in the Chinese provinces for the period of 1970-2018, the authors used principal component isolation method analysis (further - PCA) (Figure 2) [Features, 2011].

PCA is a linear compression method for multidimensional space. It is based on the rotation of axes in space to find their optimal location. The axis's location is considered optimal if it allows you to describe the maximum diversity in the data:

$\sum_{\mathrm{i}=1}^{\mathrm{n}} \sum_{\mathrm{l}=1}^{\mathrm{m}}\left(\mathrm{x}_{\mathrm{il}}-\mathrm{a}_{01}-\sum_{\mathrm{j}=1}^{\mathrm{p}} \mathrm{a}_{\mathrm{jl}} \sum_{\mathrm{q}=1}^{\mathrm{m}}\left(\mathrm{x}_{\mathrm{iq}}-\mathrm{a}_{0 \mathrm{q}}\right)\right)^{2} \rightarrow \min$,

where

$X=\left\{x_{1}, x_{2} \ldots x_{n}\right\}-$ is an array of objects (the set of all points in multidimensional space);

$k-$ is the number of parameters describing each of the objects;

$a_{0}=\frac{1}{n} \sum_{i=1}^{n} x_{i}-$ is the distribution center of all points in multidimensional space;

$a_{1} \ldots a_{m}-$ is the set of orthogonal vectors defining the axes of the selected components.

Algorithm for extracting PCA components:

1. The center of distribution of points of the array is determined $a_{0}=\frac{1}{n} \sum_{i=1}^{n} x_{i}$;

2. The direction of the first orthogonal vector $a_{1}$ (the first principal component) is determined based on the given optimization function;

3. The projection onto the first principal component is subtracted from these points:

$x_{i}:=x_{i}-a_{0}-a_{1}\left(a_{1}, \mathrm{x}_{i}\right)$.

4. The proportion of the remaining variance is estimated:

$D_{1}=\sum_{i=1}^{n} \sum_{l=1}^{p}\left(x_{i l}\right)^{2}$;

5. If the remaining variance $D_{1}$ is large, then the second principal component is introduced, and so on, until the variance in the remaining data is reduced to reasonable error.

The PCA method can be used for evaluating Chinese provinces' wilderness situation in the future.

The Beijing, Tibet, and Shandong provinces are shown as an example. For other provinces' modeling calculations, see the attached file to the paper. The structure is not unique and can be adopted for each province or different applications. The authors firstly analyzed province-level protected wildness areas and then did a decomposition using variations of the wilderness identity. The indicators could be selected to map directly to every component of wilderness protection (Equation 3).

\section{Results}

Kaya Modified Wilderness Patches Formula Results

China's thirty-one provinces were analyzed according to the modified protected wilderness formula. 


\section{Figure 1. Methodological Research Scheme}

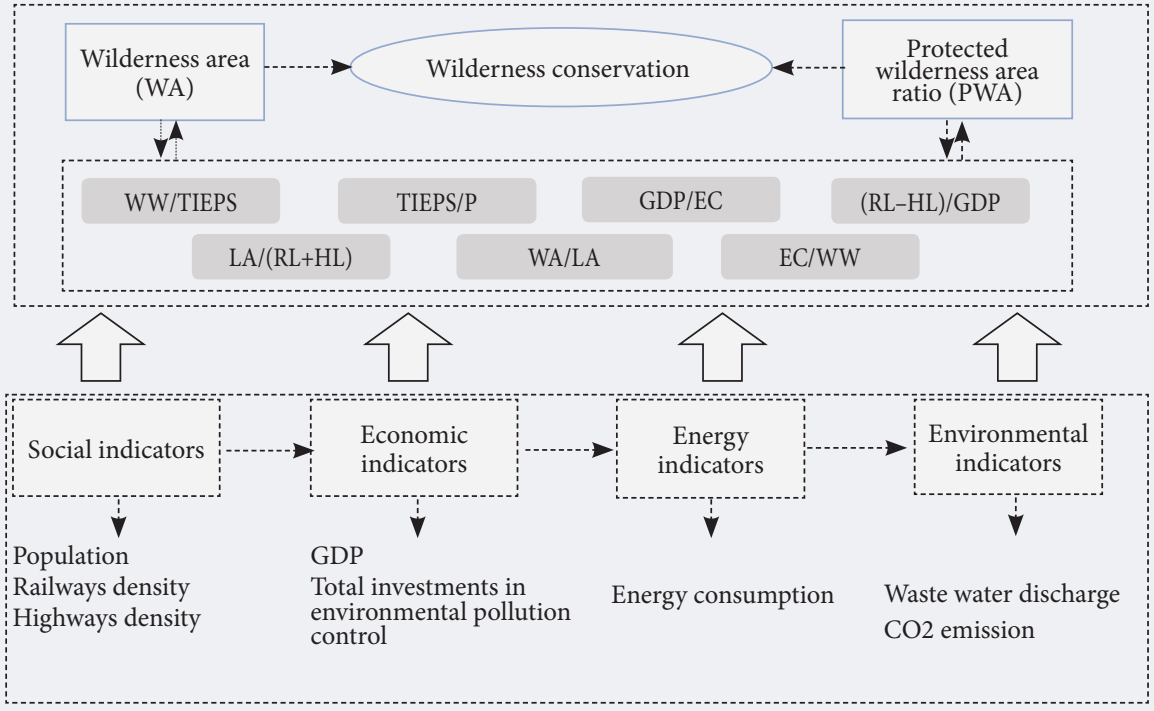

Source: compiled by the authors.

Wilderness area calculation result maps are presented in supplementary materials to the research. The authors chose only three provinces as the most "visual" for the China wilderness situation and as the most representative. The three areas are different from each other - Tibet with the greatest number of wilderness areas, Shandong with the smallest wilderness areas, and Beijing as the area with a high population density and small wilderness areas but a high level of the wilderness protection. For every province, a forecast was done up to 2030 under the multi-factors scenario (Figures 3-5). Beijing increased enormously in GDP/ $\mathrm{EC}$, that is the energy efficiency increased exceedingly over the past 40 years. Similarly, TIEPC/P increased possibly due to the difficult ecological situation in Beijing.

Beijing WA/LA has not changed since 1978. The Beijing government has been constructing natural preserves over the past 30 years, but the growing population mostly made up of outsiders $(37.9 \%$ of the permanent residents) forced Beijing to exploit the land area. Such a phenomenon also appears in other big cities, for example, in Shanghai. However, Beijing has planned negative growth of urban construction (counter-urbanization) by 2035. It aims to reduce the constructed land from the current 2,860 to 2,760 sq. $\mathrm{km}$ by 2030 . GDP/EC increased sharply, implying that Beijing's economic development is no longer heavily dependent on the consumption of energy.

Tibet's WA/LA PWA, and PWA/WA from 1978 until 2018 remained the same. At the same time, Tibet EC/WW and GDP/EC increased. There are 47 protected wilderness patches in Tibet covering an area of $41.4 \mathrm{mln}$. sq.km in total. Meanwhile, Tibet has the second largest land area in China, with a high altitude that brings about inconveniences for traffic and a stably low population balanced by birth rate, death rate, and brain drain. This results in a conspicuously high level of WA/LA and PWA. The energy efficiency grew slightly over the 40 -year period. The Chinese government is building an ecological barrier for the Qinghai-Tibet Plateau by massive afforestation. This

\section{Table 1. List of Research Indicators}

\begin{tabular}{|c|c|c|}
\hline Indicator & Code & Measure \\
\hline \multicolumn{3}{|l|}{ Social } \\
\hline Population & $\mathrm{P}$ & bln \\
\hline Railway length & $\mathrm{RL}$ & $\mathrm{km}$ \\
\hline Highway length & $\mathrm{HL}$ & $\mathrm{km}$ \\
\hline \multicolumn{3}{|l|}{ Economic } \\
\hline GDP & GDP & bln \\
\hline $\begin{array}{l}\text { Total investments in enviornmental } \\
\text { pollution control }\end{array}$ & TIEPC & bln \\
\hline \multicolumn{3}{|l|}{ Energy } \\
\hline $\begin{array}{l}\text { Energy consumption ( } 10 \text { thousands of } \\
\text { standard coal) }\end{array}$ & $\mathrm{EC}$ & $\begin{array}{l}\text { ga/ } \\
\text { population }\end{array}$ \\
\hline \multicolumn{3}{|l|}{ Environmental } \\
\hline Land area, sq. km & LA & $\begin{array}{l}\text { thousands } \\
\text { of hectares }\end{array}$ \\
\hline Wilderness patches area, & WPA & $\begin{array}{l}\text { thousands } \\
\text { of hectares }\end{array}$ \\
\hline Ratio of wilderness area & RWA & $\%$ \\
\hline $\begin{array}{l}\text { Protected wilderness area }(1000 \\
\text { sq. } \mathrm{km})\end{array}$ & PWA_SQ & $\begin{array}{l}\text { thousands } \\
\text { of hectares }\end{array}$ \\
\hline Ratio of protected wilderness areas & RPWA & $\%$ \\
\hline Ratio wilderness area/population & RWP & $\%$ \\
\hline Wastewater Discharge & WW & $\begin{array}{l}\text { thousand } \\
\text { meters cub }\end{array}$ \\
\hline Source: compiled by the authors. & & \\
\hline
\end{tabular}




\section{Figure 2. Kaya Wilderness Identity} Component Analysis

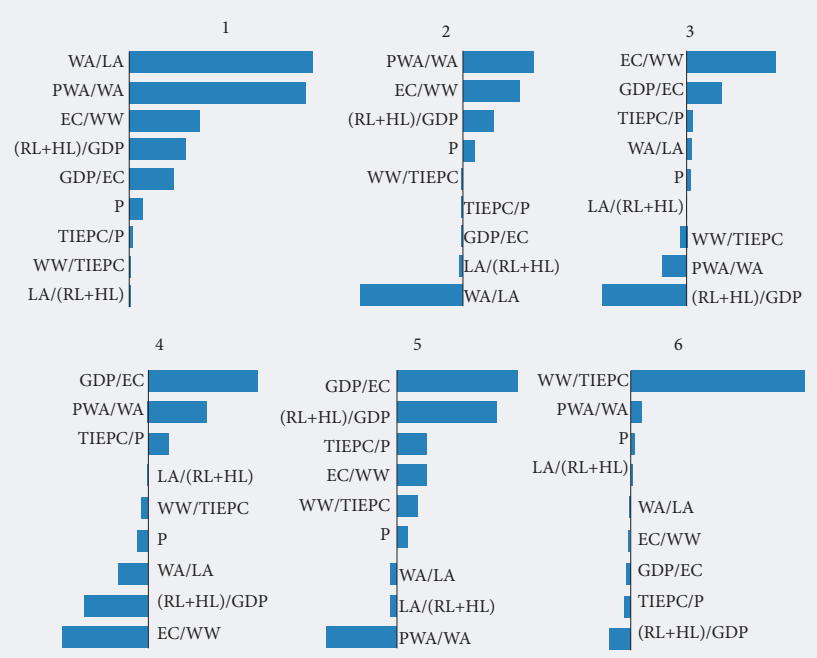

Source: compiled by the authors.

behavior induces a sharp increase of the wilderness area in Tibet and Qinghai. A large increase in the population is expected by 2030 following the opening of the Qinghai-Tibet railway. Transport convenience in Qinghai and Tibet, and industrial and economic development as well as urban construction are smoother, thus retaining more indigenous people and attracting outsiders. Therefore, by 2030 , protected areas are expected to decrease in size due to the demand for housing and food as a result of industrial development and population growth.

Shandong EC/WW rapidly increased because of the TIEPC/P lack of investments. Shandong PWA/WA stagnated for a long time. Nevertheless, $(\mathrm{R}+\mathrm{HL}) / \mathrm{GDP}$ was increased, which may be because Shandong has transferred its economic structure from one dominated by a single industry to various ones. Shandong has 86 protected wilderness areas covering $1.1 \mathrm{mln}$. sq.km., albeit colossal population growth. What is

\section{Figure 3. Beijing Analysis for the Period 1978-2018}

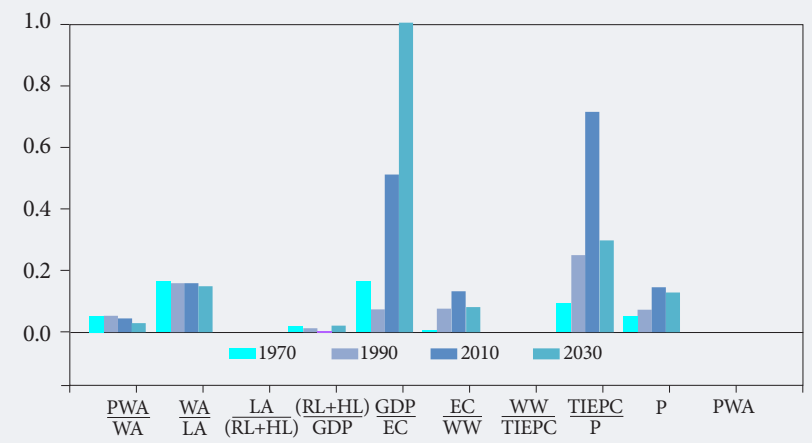

Source: compiled by the authors.

\section{Figure 4. Tibet Analysis for} the Period 1978-2018

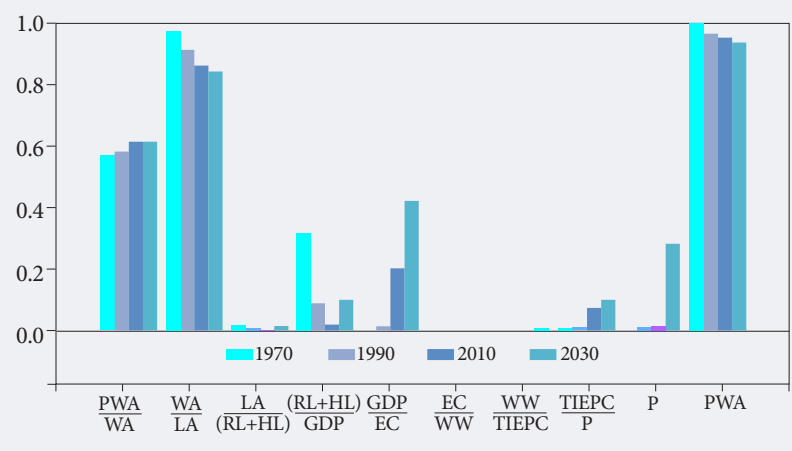

Source: compiled by the authors.

more, Shandong together with Hebei and Henan are located on the Huang-Huai-Hai Plain, where agriculture is flourishing, thus arable land occupies a large area.

\section{PCA results}

The authors evaluated every province according to the Kaya modified identity component analysis (Table 2, Figures 6-10).

First component, 33\% variability. The most significant values of this component are possessed by Tibet (47 protected wilderness patches, $41.4 \mathrm{mln}$. sq. $\mathrm{km}$ ) and Qinghai (11 protected wilderness areas, $21.8 \mathrm{mln}$. sq. $\mathrm{km}$ ), Xinjiang (27 protected wilderness patches, $21,494,365$ sq.km), and Sichuan (167 protected wilderness patches, 9,006,856 sq.km). The lowest wilderness indicators are seen in Beijing (20 protected wilderness areas, 133,966 sq.km.) and Hebei (35 protected wilderness areas, 587,268 sq. $\mathrm{km}$ ) because of the increasing populations in these provinces. On the other hand, Hebei's industrial system is strongly based on coal, steel, and textile industries, which all rely heavily upon land resources.

Second component, $25 \%$ variability. On the one hand, there are provinces with large wilderness territories,

\section{Figure 5. Shandong Province Analysis for the Period 1978-2018}

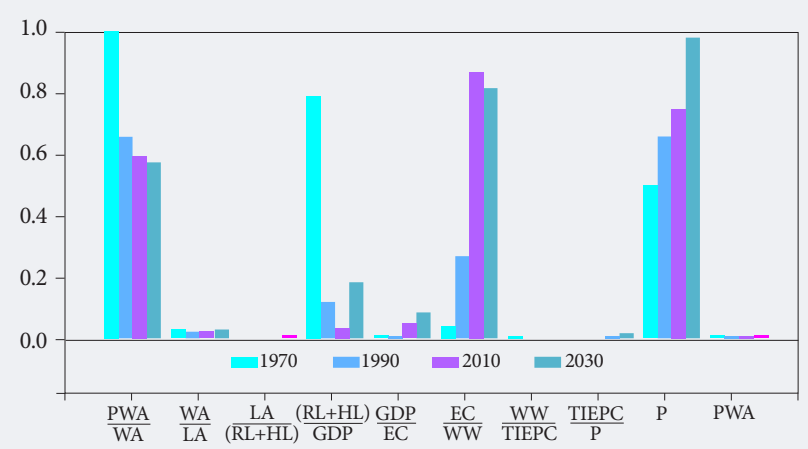

Source: compiled by the authors. 
Table 2. Kaya Wilderness Identity Component Analysis

\begin{tabular}{|l|r|r|r|r|r|r|}
\hline & \multicolumn{1}{|c|}{$\mathbf{1}$} & \multicolumn{1}{c|}{$\mathbf{2}$} & \multicolumn{1}{c|}{$\mathbf{3}$} & \multicolumn{1}{c|}{$\mathbf{4}$} & \multicolumn{1}{c|}{$\mathbf{5}$} & \multicolumn{1}{c|}{$\mathbf{6}$} \\
\hline PWA/WA & 0.648626 & 0.506946 & -0.187239 & 0.343734 & -0.406296 & 0.037251 \\
\hline WA/LA & 0.663000 & -0.725034 & 0.051394 & -0.175843 & -0.019821 & -0.009151 \\
\hline LA/(RL+HL) & 0.014633 & -0.011236 & 0.003877 & -0.008797 & -0.035328 & 0.008868 \\
\hline (RL+HL)/GDP & 0.206144 & 0.219079 & -0.647432 & -0.381764 & 0.568404 & -0.128007 \\
\hline GDP/EC & 0.164741 & -0.007912 & 0.262397 & 0.648581 & 0.659313 & -0.028756 \\
\hline EC/WW & 0.257215 & 0.400941 & 0.683103 & -0.513748 & 0.169738 & -0.009462 \\
\hline WW/TIEPC & 0.015156 & 0.004186 & -0.060457 & -0.043689 & 0.116060 & 0.989485 \\
\hline TIEPC/P & 0.017780 & -0.007498 & 0.054383 & 0.119379 & 0.174957 & -0.041277 \\
\hline $\mathrm{P}$ & 0.056218 & 0.091213 & 0.031995 & -0.065965 & 0.051136 & 0.019061 \\
\hline Sorc:con & & & & &
\end{tabular}

Source: compiled by the authors.

such as Xinjiang, on the other - Shandong with a high proportion of protected areas and low emissions per unit of energy consumed. This component ranks the provinces by the degree of the struggle to preserve the environment from Xinjiang and Inner Mongolia to Shandong. A positive trend is growing in almost every province, especially in Sichuan.

Third component, $17 \%$ variability. This phenomenon sets the difference between provinces and the overall trend in their development. The trend is associated with two correlated factors: the values of GDP per kilometer of roads (in the formula it is written in the reverse form: the number of roads per 1 unit of GDP) and the amount of energy consumed per 1 unit of flows. Both of these indicators are growing in all provinces. To a greater extent, this was manifested in Guangdong, to a lesser extent in Yunnan.

Fourth component, 9\% variability. This is related to energy consumption and its share of GDP and wilderness areas. The developed territories with a large number of non-energy-efficient industries (like Guangdong) have a small value of the component, at the other pole are Beijing, Hainan, and Taijing, where high energy efficiency is the key to survival.
Fifth and sixth components, $8 \%$ and $4 \%$ variability, respectively. These distinguished the difference between small provinces. The fifth component reflects the difference in GDP, while the sixth component reflects the difference in the area. These components are not essential for the complete analysis.

Then, the authors used the first and second components to build trends concerning wilderness conservation in China from 1970 to 2018 (Figure 10). In Figure 10, the red lines mean devastated, emptied lands. Blue lines mean fresh wilderness patches.

Figure 10 demonstrates that Tibet, Qinghai, and Xinjiang have the most wilderness areas. Sichuan and Gansu have a trend toward exhausted, drained lands. Xinjiang produces a lot of oil and gas and is part of the "One belt - One road" territory. Tibet and Qinghai have many wilderness patches, but a low level of economic development due to inconvenient transport infrastructure caused by the high altitude (the first railway in Tibet and Qinghai was opened on July 1, 2006 with the length of 1,956 km).

Gansu and Sichuan tend toward economic development and may therefore risk moving away from wilderness zones. Inner Mongolia, Heilongjiang, and

Figure 6. Trends in the First Component Analysis after PCA Compression

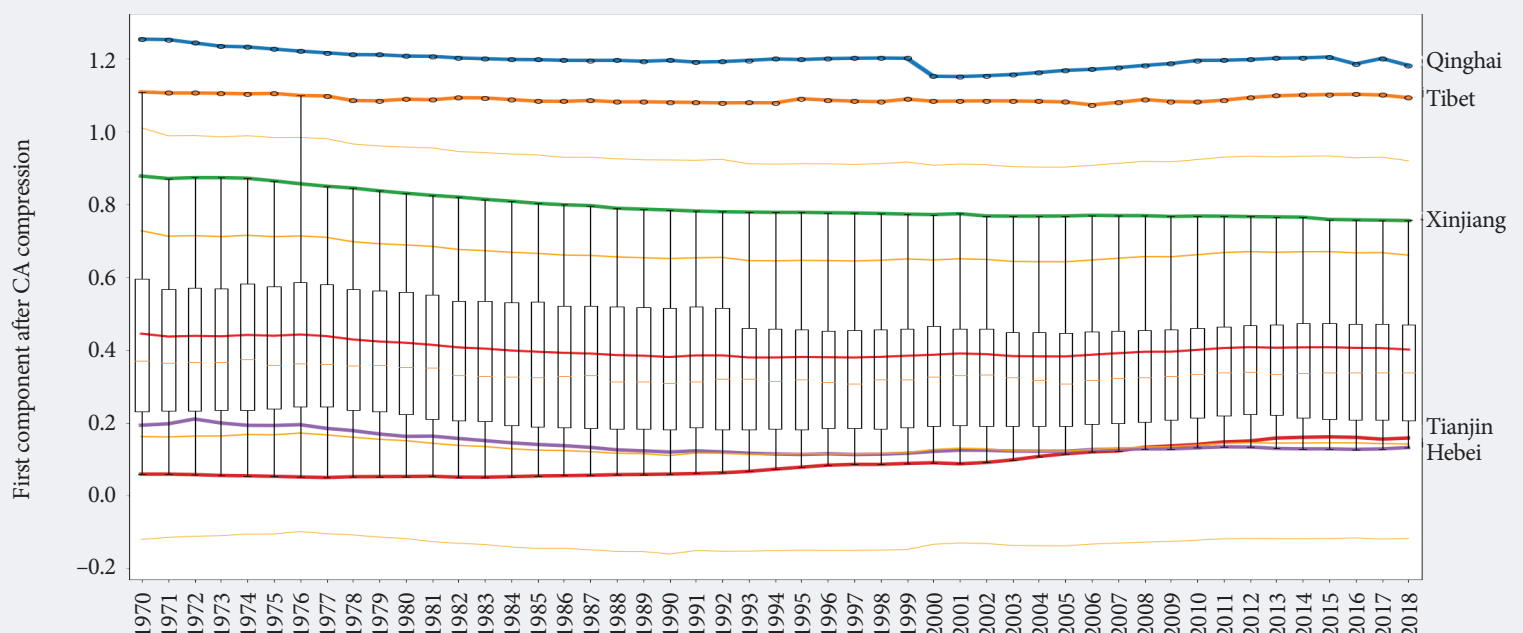

Source: compiled by the authors. 


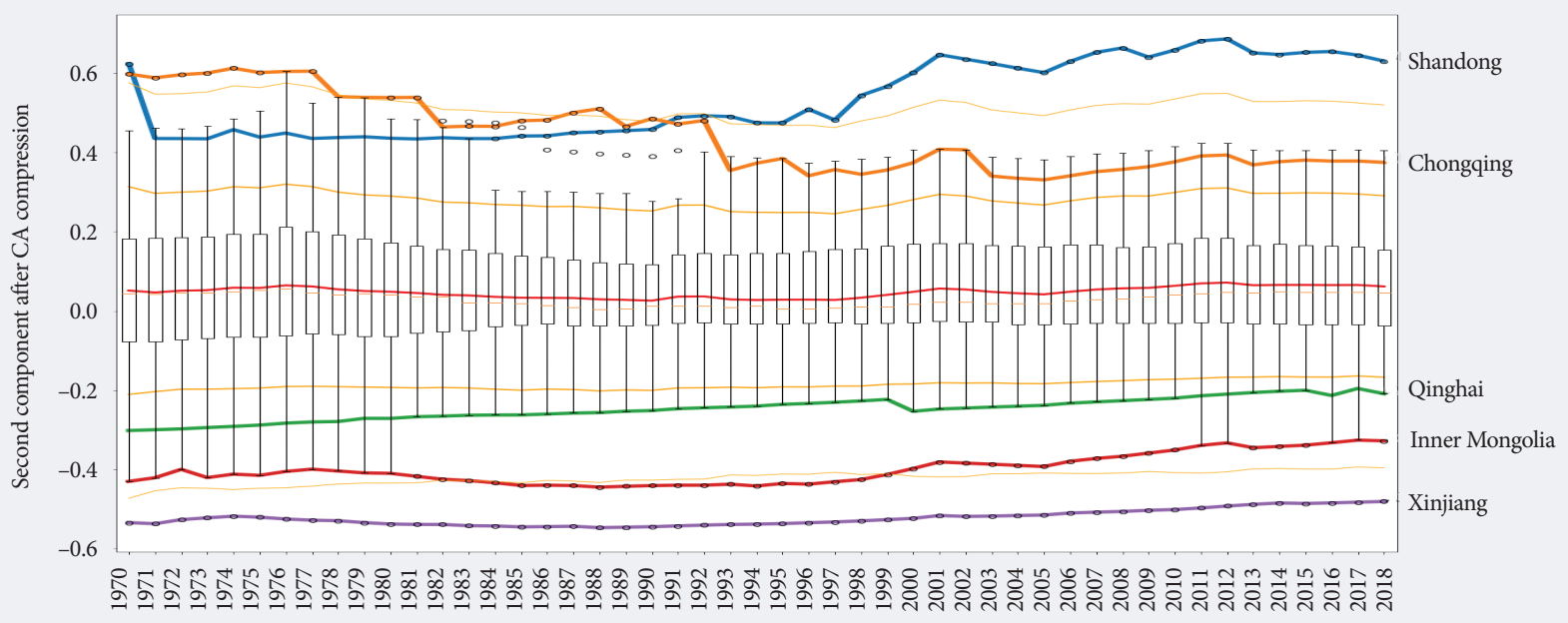

Source: compiled by the authors.

Jilin, all in the northern part of China, have few wilderness patches. All other provinces tend to have more devastated lands.

Figure 10 shows exciting results: in the 1970s, the wilderness situation in the provinces was not the same as it is now. For example, Anhui in the 1970s had the same features as Hunnan, however, nowadays it is like Guanxi. Chongqing and Hubei in 2018 also have transitioned into similar conditions. Nowadays, all "mini" provinces are linked together. It was also noticed that all the provinces in the middle of China with small land areas and mild altitudes were huddled, partly because they have much in common with regard to economic, social, and geographical indicators, so they usually take similar measures. For example, these provinces are centers of the manufacturing and coal industry in China.
The analysis showed that Tibet, Xinjiang, Hainan, and Qinghai have the largest wilderness areas for every person per capita. Shandong, Hebei, Jiangsu, Jilin, Hubei, Zhejiang, and Liaoning on the contrary, have the smallest wilderness areas per capita. Shandong has the second largest population among the provinces in China. Indeed, the highest wilderness area ratio can be observed in Tibet, Gansu, Guanxi, Yunnan, Xinjiang, Qinghai, Guizhou, and Inner Mongolia. The lowest wilderness area ratio can be observed in the Shandong, Henan, Jiangsu, Zhejiang, Chongqing, and Hubei provinces. Thus, in these provinces industries are fully developed and have large population densities (Shandong is the second, Henan is the third) within a small area. Zhejiang has the most significant growth rate together with Guangdong concerning population. In 2018, Zhejiang's population

\section{Figure 8. Trends in the Third Component after PCA Compression}

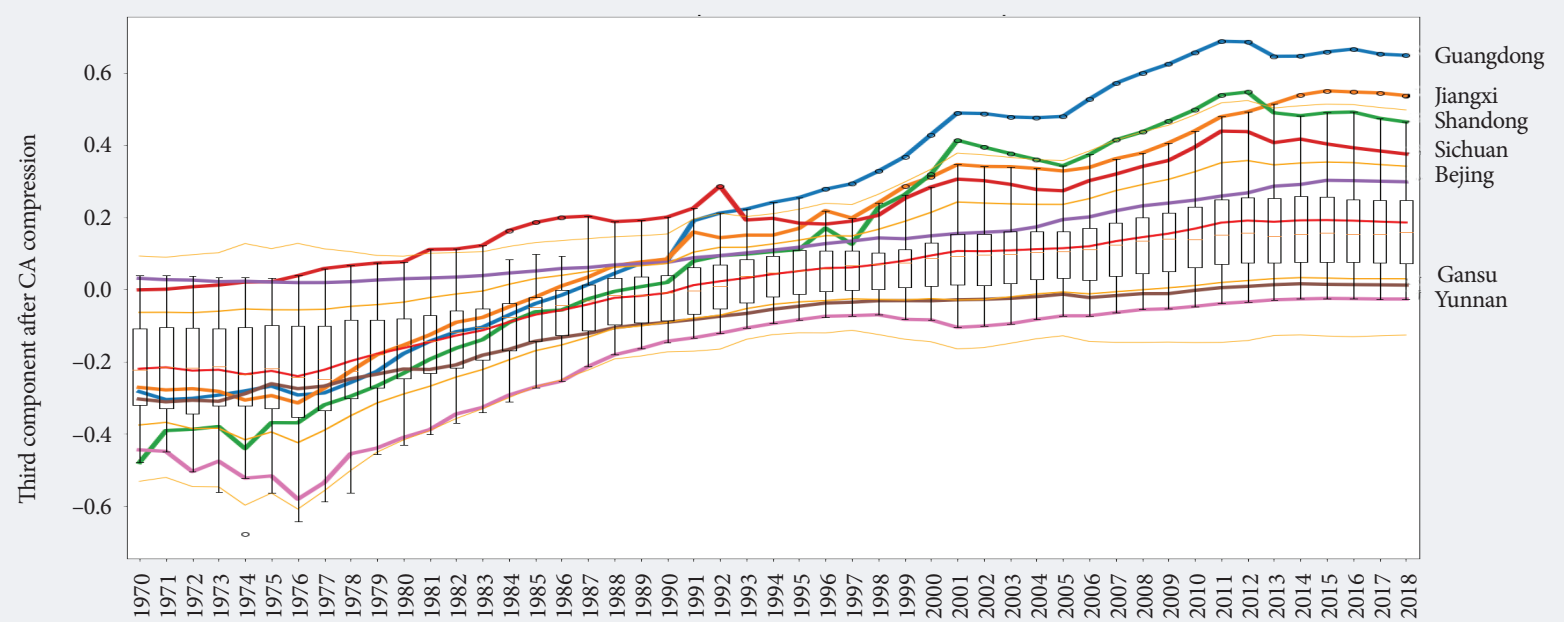

Source: compiled by the authors. 


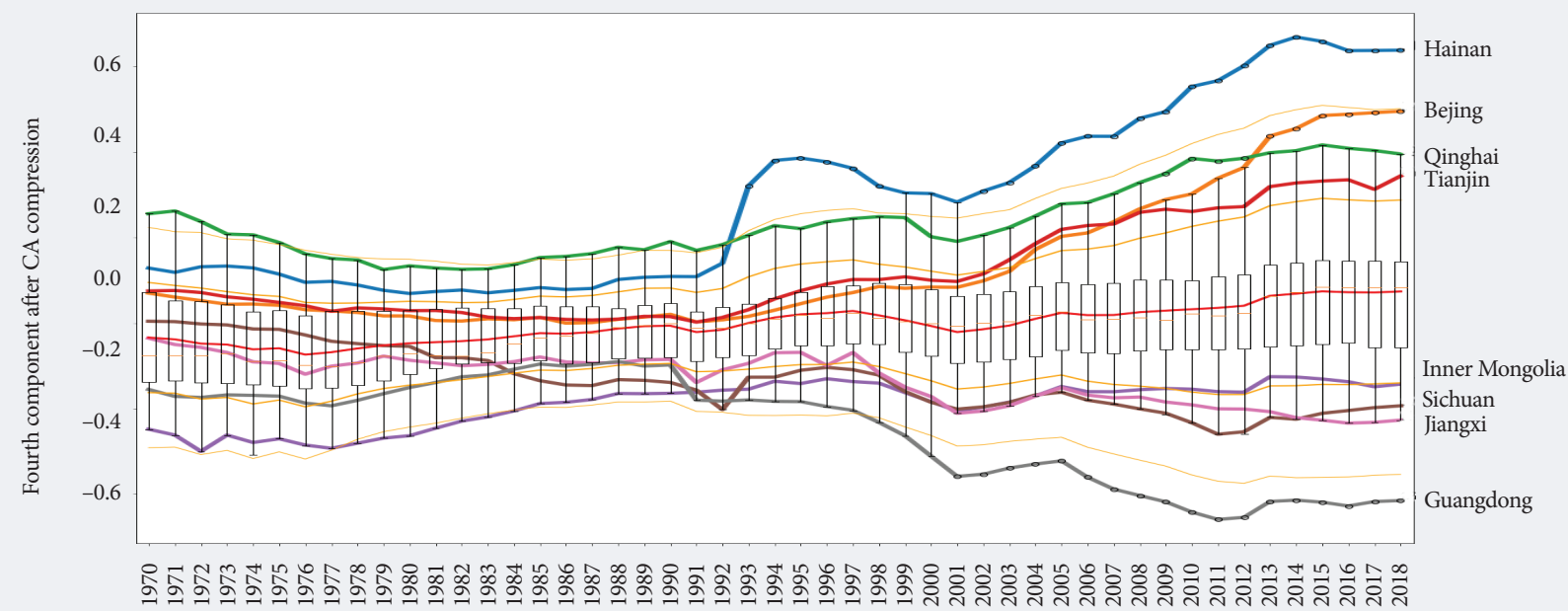

Source: compiled by the authors.

increased by $1.41 \%$. Shandong has the highest level of economic potential among the top three Chinese provinces. Inner Mongolia, Heilongjiang, and Jilin are all in the northern part of China and have small wilderness areas. All other provinces have a tendency toward devastated lands. Tibet and Qinghai have many wilderness patches, but a low level of economic development. However, these areas are the main areas for the construction of the "One Belt-One Road Initiative”.

\section{Conclusions and Recommendations}

The authors found that the RWA/PWA evaluation alongside the modified Kaya wilderness identity components analysis produced fruitful and controversial results. In the 1970s, the wilderness situation of the Chinese provinces was not the same as it is nowadays. For example, the situation of Anhui in the 1970s was similar to that of the Hunnan province, while nowadays it is closer to Guanxi province due to the different environmental policies and regulations carried out. Chongqing is the neighbor of Hubei and nowadays it also has a similar wilderness situation. It has been observed that all the provinces in the middle of China with small land areas and mild altitudes were huddled, partly because they have much in common economically, socially, and geographically, so they usually take similar political measures.

China needs to develop the environmental economy in the interest of sustainability and economic competitiveness. Future research areas are based on wilderness geography to support green economy projects and programs [Bocharnikov, 2019]. As a consequence of ensuring "green growth", conflicts between ecological interests and business priorities should be mini- mized. The same conflict can be observed between environmental priorities and industrial programs and the creation of new and the modernization of existing transport corridors [Vasiev et al., 2020]. China is still a largely agricultural country with a large population. In order to expand the arable land area, people are willing to destroy the forest and grass cover to open up the land and reclaim the lakes for farmland, which has caused great harm to the environment. The level of soil erosion is very severe in China.

The authors' opinion is that one of the reasons for this is that the principles of ecological economics and political ecology do not take into account laws that are developed in the real economy given that China has already started to develop territories that were considered wilderness areas before. The authors observe the following trends:

- In most Chinese provinces, the situation is leveled smoothly (development trends are moving away from wilderness). Meanwhile, an exception occurs in small provinces as they become similar to each other concerning wilderness conservation trends. From the perspective of ecological environmental management, it is mainly a natural ecosystem and watershed unit or airspace unit;

- However, the situation in China's northwestern provinces differs greatly. The geographical and regional background in such locations varies significantly, so it is impossible to regard them as a whole system and analyze them merely in the geographic dimension;

- In the 1970s, the first trend for moving out from wilderness began in the following provinces: Hunan, Henan, and Hebei. Nowadays, the situation is similar in all other provinces. They have 
Figure 10. Trends in Chinese Provinces' Wilderness Conservation for the Period 1970-2018

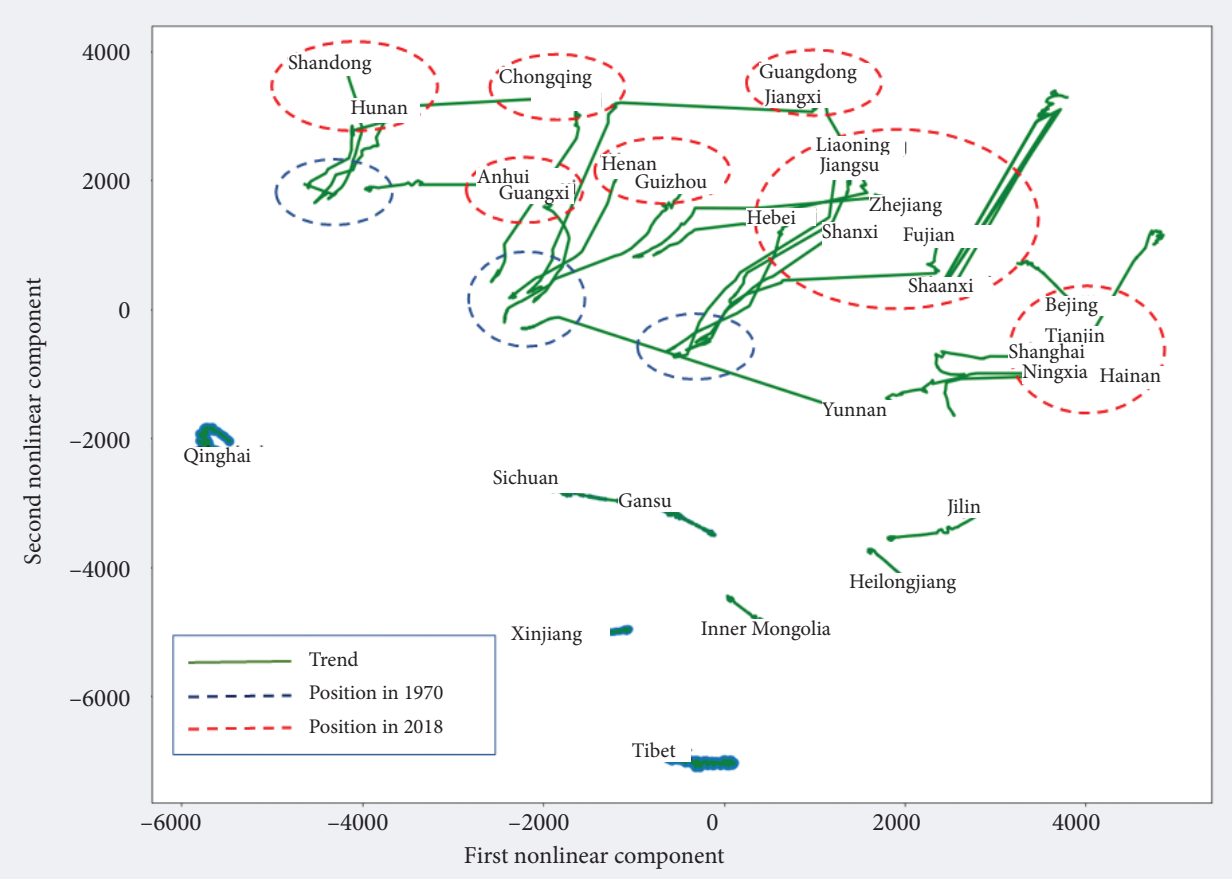

Note: the red lines mean devastated, emptied lands; blue lines mean fresh wilderness patches.

Source: compiled by the authors.

all moved away from wilderness conservation. Moreover, the analysis illustrates a slow trend away from the wilderness in China's inner-middle and inner-western provinces, such as Anhui, Hubei, and Jiangxi as a result of their rapid development. Indeed, Jiangxi, Hubei, and Anhui have the highest economic potential among all provinces in China.

There are many valuable practices in the world for developing the "green economy" and minimizing its impact on nature. States have developed different points of view concerning the green economy: for developed countries in the first place this concerns jobs and welfare competition, while for developing countries the focus is on sustainable development and solving problems of poverty, and finally, for the BRICS countries, states emphasize energy efficiency. Nowadays, China's new "ecological civilization framework" is one of the most effective initiatives aligning green economic growth with wilderness protection. The new ecological legislation covers all provinces and considers nature conservation throughout the whole country [Xi, 2000].

The authors suggested a few ways of developing wilderness research studies in the future:

- Develop methods to measure how economic factors influence wilderness areas;

- Develop multidisciplinary methods to study the transversal linkage between social, energy, and environmental indicators and the wilderness patches.

- Develop methods to illustrate the cost of wilderness for humanity.

Therefore, when dealing with the relationship between sustainable growth and wilderness conservation, the government needs to insist upon implementing a green sustainable policy. The CPC has put forward measures such as reverting farmland to forests, grasslands, and lakes, and returning grazing land to grasslands. The challenge lies in increasing data availability on wilderness in China and the rest of the world and this must be addressed by involving appropriate definitional and habitat criteria and support plans for protecting and monitoring such areas effectively. The implementation of these measures would increase China's forest coverage, significantly expand the area of lakes, and regulate the climate and flood flow. China's ecological environment is expected to be significantly improved.

The research was accomplished with the support of the Harbin Engineering University's Fundamental Research Fund for the Central Universities "Sustainable Development of Green Silk Road from a Complex Network Perspective" (Project No. 3072020CFJ0901) and Harbin Engineering University's Fundamental Research Funds for the Central Universities "Digitally Driven Green Intelligent Manufacturing and Energy Ecological Governance Research" (Project No. 3072020CFW0903). The authors declare no conflicts of interest. 


\section{References}

Baklanov P.Y., Bocharnikov V.N., Egidarev E.G. (2018) The "Silk Road of China" and economic priorities of the Pacific Russia. IOP Conference Series: Earth and Environmental Science, 190(1), 1-8. DOI: 10.1088/1755-1315/190/1/012044. https:// iopscience.iop.org/article/10.1088/1755-1315/190/1/012044/pdf, accessed 15.11.2020.

Bocharnikov V., Huettman F. (2019) Wilderness Condition as a Status Indicator of Russian Flora and Fauna : Implications for Future Protection Initiatives. International Journal of Wilderness, 25(1), 26-39. https://ijw.org/wilderness-condition-statusindicator-russian-flora-fauna/, accessed 26.10.2020.

Bocharnikov V.N. (2019) Concepts and Measures for Maintaining Wilderness and Landscape Biodiversity in Anthropocene. In: Innovations in Landscape Research (eds. L. Mueller, F. Eulenstein), Heidelberg, New York, Dordrecht, London: Springer, 167-190. https://doi.org/10.1007/978-3-030-30069-2.

Cao Y., Carver S., Yang R. (2019) Mapping wilderness in China: Comparing and integrating Boolean and WLC approaches. Landscape and Urban Planning, 192, 103636. https://doi.org/10.1016/j.landurbplan.2019.103636

Ceauşu S., Gomes I., Pereira H.M. (2015) Conservation Planning for Biodiversity and Wilderness: A Real-World Example. Environmental Management, 55(5), 1168-1180. https://doi.org/10.1007/s00267-015-0453-9

Cleveland C., Costanza R., Hall C.A.S., Kaufmann R. (1984) Energy and the U.S. economy: A biophysical perspective. Science, 225(4665), 890-897. DOI: 10.1126/science.225.4665.890

Connor D., Ford J.(2014) Increasing the Effectiveness of the "Great Green Wall" as an Adaptation to the Effects of Climate Change and Desertification in the Sahe. Sustainability, 6(10), 7142-7154. https://doi.org/10.3390/su6107142

Costanza R. (1989) What is ecological economics? Ecological Economics, 1(1), 1-7. https://doi.org/10.1016/09218009(89)90020-7

Costanza R., Giovannini E., Lovins L.H., Mcglade J., Pickett K., Ragnarsdottir K., Roberts D., De Vogli R., Wilkinson R. (2014) Time to leave GDP behind. Nature, 505(3), 283-285.

Costanza R., de Groot R., Braat L., Kubiszewski I., Fioramonti L., Sutton P., Farber S., Grasso M. (2017) Twenty years of ecosystem services: How far have we come and how far do we still need to go? Ecosystem Services, 28(A), 1-16. https://doi. org/10.1016/j.ecoser.2017.09.008

Daly H.E. (2007) Ecological Economics and Sustainable Development. Selected Essays, Cheltenham: Edward Elgar.

Features K. (2011) Ordinary Least-Squares Regression. In: The Multivariate Social Scientist (eds. G.D. Hutcheson, N. Sofroniou), Thousand Oaks, CA: Sage, 56-113. DOI: 10.4135/9780857028075.d49

Frelich L.E., Reich P.B. (2009) Wilderness Conservation in an Era of Global Warming and Invasive Species: A Case Study from Minnesota's Boundary Waters Canoe Area Wilderness. Natural Areas Journal, 29(4), 385-393. https://doi. org/10.3375/043.029.0405

Hall C.A.S., Lambert J.G., Balogh S.B. (2014) EROI of different fuels and the implications for society. Energy Policy, 64, 141152. https://doi.org/10.1016/j.enpol.2013.05.049

Kaya Y., Yokoburi K. (1997) Environment, energy, and economy: Strategies for sustainability, Tokyo: United Nations University Press.

Kosman E., Burgio K.R., Presley S.J., Willig M.R., Scheiner S.M. (2019) Conservation prioritization based on trait-based metrics illustrated with global parrot distributions. Diversity and Distributions, 25(7), 1156-1165. https://doi.org/10.1111/ ddi. 12923

Kuiters A.T., van Eupen M., Carver S., Fisher M., Kun Z., Vancura V. (2013) Wilderness register and indicator for Europe, Brussels: European Commission.

Lester R., Finan A. (2009) Quantifying the impact of proposed carbon emission reductions on the US energy infrastructure (Energy Innovation Working Paper Series 004), Zurich: ETH.

Locke H. (2009) Canada Increases Policy Goals. International Journal of Wilderness, 15(1), 4-14. http://www.wild.org/wpcontent/uploads/2009/04/locke-apr09-ijw_sm.pdf, accessed 23.10.2020.

Meadows D.H., Meadows D.L., Randers J., Behrens III W.W. (1972) The Limits to Growth (1st ed.), New York: Universe Books.

Mittermeier R.A., Mittermeier C.G., Brooks T.M., Pilgrim J.D., Konstant W.R., da Fonseca G.A.B., Kormos C. (2003) Wilderness and Biodiversity Conservation. PNAS, 100 (18), 10309-10313. https://doi.org/10.1073/pnas.1732458100

Nash R.F.C.M. (2014) Wilderness and the American Mind (5th ed.), New Haven, CT: Yale University Press.

Palmer G. (2018) A Biophisical Perspective of IPCC Integrated Energy Modeling. Energies, 11(4), 839. https://doi.org/10.3390/ en11040839

Proctor K.W., Murthy G.S., Higgins C.W. (2021) Agrivoltaics Align with Green New Deal Goals while Supporting Investment in the US' Rural Economy. Sustainability, 13(1), 137. https://doi.org/10.3390/su13010137

Rasker R. (2006) An exploration into the economic impact of industrial development versus conservation on western public lands. Society and Natural Resources, 19(3), 191-207. https://doi.org/10.1080/08941920500460583

Sahanatien V. (2007) Land Claims as a Mechanism for Wilderness Protection in the Canadian Arctic. In: USDA Forest Service Proceedings RMRS-P-49, Washington, D.C.: USDA, 199-203. https://www.fs.fed.us/rm/pubs/rmrs_p049/rmrs_ p049_199_203.pdf, accessed 23.10.2020.

Sandbrook C. (2015) What is conservation? Oryx, 49(4), 565-566. https://doi.org/10.1017/S0030605315000952

Shi B., Yang H.,Wang J., Zhao J. (2016) City green economy evaluation: Empirical evidence from 15 sub-provincial cities in China. Sustainability, 8(6), 551. https://doi.org/10.3390/su8060551 
Steblyanskaya A., Wang Z., Bragina Z. (2019) Financial Sustainable Growth Theory as a Result of Interaction with Energy, Social and Environmental Factors. Finance: Theory and Practice, 23(2), 134-152. https://doi.org/10.26794/2587-5671-201923-2-134-152 (in Russian).

Tang X., McLellan B.C., Snowden S., Zhang B., Höök M. (2015) Dilemmas for China: Energy, economy and environment. Sustainability, 7(5), 5508-5520. https://doi.org/10.3390/su7055508

Tang X., Jin Y., Feng C., McLellan B.C. (2018) Optimizing the energy and water conservation synergy in China: $2007-2012$. Journal of Cleaner Production, 175, 8-17. https://doi.org/10.1016/j.jclepro.2017.11.100

Vaghefi N., Siwar C., Aziz S.A.A.G. (2015) Green Economy: Issues, Approach and Challenges in Muslim Countries. Theoretical Economics Letters, 5, 28-35. http://dx.doi.org/10.4236/tel.2015.51006

Vasiev M., Bi K., Denisov A., Bocharnikov V. (2020) How Coronavirus Pandemics (COVID-19) Influences Chinese Economic Sustainability. Foresight and STI Governance, 14(2), 7-22. DOI: 10.17323/2500-2597.2020.2.7.22

Ward J.D., Sutton P.C., Werner A.D., Costanza R., Mohr S.H., Simmons C.T. (2016) Is Decoupling GDP Growth from Environmental Impact Possible? PLoS ONE, 11(10), e0164733. https://doi.org/10.1371/journal.pone.0164733.

Williams J.A. (1996) “The chords of the German soul are tuned to nature": The movement to preserve the natural Heimat from the Kaiserreich to the third Reich. Central European History, 29(3), 339-384. https://doi.org/10.1017/S0008938900013674

Wuerthner G. (2018) Anthropocene Boosters and the Attack on Wilderness Conservation. The Ecological Citizen, 1(2), 161166.

Xi J. (2020) Ecological economics in China: From origins, to inertia, to rejuvenation. In: Sustainable Wellbeing Futures. A Research and Action Agenda for Ecological Economics (eds. R.Costanza, J.D. Erickson, J. Farley, I.Kubiszewski), Cheltenham (UK): Edward Elgar Publishing, 61-89. https://doi.org/10.4337/9781789900958.00013

Zimmerman D.W., Zumbo B.D., Williams W.R. (2003) Bias in Estimation and Hypothesis Testing of Correlation. Psicológica, 24, 133-158. DOI: $10.1121 / 1.4831544$ 